\title{
PREDIKSI JUMLAH PENERIMAAN MAHASISWA BARU DENGAN METODE SINGLE EXPONENTIAL SMOOTHING (STUDI KASUS: AMIK ROYAL KISARAN)
}

\author{
Wiwin Handoko \\ Program Studi Sistem Informasi, STMIK Royal Kisaran \\ Email: win.van.handoko@gmail.com
}

\begin{abstract}
A problem requires a solution to solve it. One of them is by using Prediction (Forcasting). Prediction is used to assess the prediction of conditions in the future. at AMIK Royal Kisaran, when it comes to making lecture schedules often hampered because there is no estimated number of students. The data used in this study is the data history of the last 15 Academic Years, from 2003/2004 to 2017/2018. Then the data is processed with the Single Exponential Smoothing Method. Alpha value $0<\alpha<1$. Single Exponential Smoothing makes a comparison with the alpha value until alpha is found which has the minimum error. To find the value of the error, the MSE (Mean Square Error) method is used. The results of the testing of this method are in the academic year 2018/2019 prediction of the number of students for the Informatics Management Study Program as many as 89 people and for Students for the Computer Engineering Study Program as many as 30 people. The Single Exponential Smoothing method can predict the number of students in the next period.
\end{abstract}

Keywords: Prediction; Number of Students; Single Exponential Smoothing; Alpha Value; MSE

\begin{abstract}
Abstrak: Suatu masalah memerlukan sebuah solusi untuk menyelesaikannya. Salah satunya dengan menggunakan Prediksi (Forcasting). Prediksi digunakan untuk menilai prakiraan keadaan dimasa. di AMIK Royal Kisaran, ketika akan membuat jadwal kuliah sering terhambat karena tidak adanya perkiraan jumlah mahasiswa. Data yang digunakan pada penelitian ini adalah histori data 15 Tahun Akademik terakhir, mulai 2003/2004 sampai dengan 2017/2018. Kemudian data diolah dengan Metode Single Exponential Smoothing. Nilai alpha $0<\alpha<1$. Single Exponential Smoothing melakukan perbandingan dengan nilai alpha tersebut sampai ditemukan alpha yang memiliki error paling minimum. Untuk mencari nilai Error digunakan Metode $M S E$ (Mean Square Error). Hasil dari pengujian terhadap metode ini adalah pada Tahun akademik 2018/2019 prediksi jumlah Mahasiswa untuk Program Studi Manajemen Informatika sebanyak 89 orang dan untuk Mahasiswa untuk Program Studi Teknik Komputer sebanyak 30 orang. Metode Single Exponential Smoothing dapat membantu prediksi jumlah mahasiwa pada satu periode kedepan
\end{abstract}

Kata kunci: Prediksi; Jumlah Mahasiswa; Single Exponential Smoothing; Nilai Alpha; MSE

\section{PENDAHULUAN}

Kampus merupakan Institusi Pendidikan Tinggi atau Lembaga yang dimanfaatkan sebagai sarana pendidikan untuk melaksanakan program bimbingan, pengajaran dan latihan agar mahasiswa mampu mengembangkan kompetensinya dengan baik dan terarah. Kompetensi mahasiswa dapat berupa aspek moral, 
intelektual, spiritual, emosional, dan sosial. Untuk menggapai tujuan tersebut, kampus harus meningkatkan baik dalam bagian sarana maupun prasarana. Sarana mencakup Fasilitas Gedung, Laboratorium Komputer, Kantin, Musholla, Parkir dan lainnya. Prasarana mencakup kelengkapan dan keteraturan Administrasi. Namun untuk meraih dan membangun hal tersebut tidak bisa dikatakan mudah, pastinya banyak masalah yang harus diperbaiki. untuk itu harus ada perencanaan yang tidak hanya efektif tetapi juga harus efisien khususnya dalam organisasi saat mengambil kebijakan atau keputusan yang sangat signifikan [1].

AMIK Royal Kisaran merupakan institusi Pendidikan Tinggi penyelenggara Pendidikan Diploma 3 Tahun yang mempunyai dua Prodi, Teknik Komputer dan Manajemen Informatika. AMIK Royal selalu komitmen untuk meningkatkan kualitas maupun kuantitas baik sarana maupun prasarana setiap tahunnya. Namun untuk hal meraih hal tersebut, AMIK Royal juga menghadapi masalah. Salah satunya kesulitan untuk membuat jadwal kuliah untuk Program Studi Teknik Komputer Manajemen Informatika karena tidak adanya prakiraan atau prediksi jumlah mahasiswa baru. Untuk itu harus dibuat sebuah solusi untuk menyelesaikan masalah tersebut, salah satunya dengan menggunakan Prediksi (Forcasting). Peranan forcasting begitu penting misalnya untuk bagian pemasaran, organisasi maupun SDM, namun bukan sebagai pengganti perencanaan melainkan salah satu aspek dari perencanaan [2].

\section{Prediksi (Forcasting)}

Menurut KBBI prediksi memiliki padanan kata yaitu peramalan; prakiraan yang memiliki arti meramalkan sesuatu berdasarkan perhitungan yang hasilnya rasional dan ketepatan analisis data. Peramalan akan menggunakan histori data dalam perhitungannnya sehingga Peramalan merupakan suatu seni dalam ilmu pengetahuan untuk memprediksi suatu keadaan dimasa mendatang [3]. Secara umum manfaat peramalan yaitu:

1. Sebagai alat bantu perencanaan yang efektif;

2. Untuk membantu menentukan kebutuhan berbagai sumber daya di masa mendatang;

3. Alat bantu alternatif untuk proses pengambilan keputusan yang lebih baik.

\section{Metode Single Exponential Smoothing}

Cara ini berasumsi bahwa data berfluktuasi disekitar nilai mean yang tetap dan tanpa pola pertumbuhan yang konsisten. Metode SES cocok untuk memprediksi hal-hal yang fluktuasinya tidak teratur (acak) [4]. Adapun rumus metode $S E S$ adalah

$$
\begin{aligned}
& \mathbf{F t}+\mathbf{1}=\boldsymbol{\alpha} \mathbf{X t}+(\mathbf{1 - \alpha}) \mathbf{F t} \\
& \text { dimana: } \\
& \mathrm{Ft}+1=\text { Prediksi untuk periode ke } \mathrm{t}+1 \\
& \mathrm{Xt} \quad=\text { Nilai riil/aktual periode ke } \mathrm{t} \\
& \mathrm{Ft} \quad=\text { Prediksi untuk periode ke } \mathrm{t} \\
& \alpha \quad=\text { bobot yang menunjukkan } \\
& \text { konstanta penghalusan }(0<\alpha<1)
\end{aligned}
$$

\section{Mean Squared Error (MSE)}

Mengukur tingkat akurasi suatu periode peramalan dapat dilakukan dengan mencari selisih besaran (ukuran kesalahan peramalan) data peramalan terhadap data aktual. Dengan membandingkan ukuran kesalahan terkecil, sehingga nilai peramalan dijadikan sebagai dasar untuk menentukan kebutuhan dimasa mendatang. mengukur tingkat kesalahan dapat diuji menggunakan beberapa 
metode diantaranya menggunakan $M S E$. $M S E$ dihitung berdasarkan jumlah dari selisih data peramalan dengan data aktual. semakin kecil nilai $M S E$ maka ramalan semakin akurat [5]. Adapun rumus menghitung MSE sebagai berikut:

$\mathrm{MSE}=\frac{\sum_{t=1}^{n}(X t-F t)^{2}}{n}$

dimana:

MSE : Mean Squared Error

$\mathrm{Xt}$ : Nilai aktual pada periode $\mathrm{t}$

$\mathrm{Ft}$ : Nilai peramalan pada periode $\mathrm{t}$

n : Banyaknya data

\section{METODE}

Metodologi merupakan langkahlangkah atau kerangka kerja teoritis yang dimaksudkan untuk mengerjakan penelitian dengan cara-cara tertentu untuk memperoleh kebenaran. Berhasil atau tidaknya penelitian ini ditentukan oleh metodologi yang akan dipakai. Metodologi penelitian ini memuat tentang kerangka kerja penelitian. Tahapannya meliputi, mengidentifikasi masalah, menganalisis masalah, menentukan tujuan, mempelajari literatur, data apa yang dikumpulkan, analisis data, menganalisa metode SES dan MSE, perancangan model, implementasi sistem, pengujian hasil serta hasil dan pembahasan

\section{HASIL DAN PEMBAHASAN}

Pada tahapan ini, hal yang pertama dilakukan adalah menganalisa sistem. Historis data penerimaan mahasiswa baru akan dihitung menggunakan metode Single Exponential Smoothing untuk mencari berapa prediksi jumlah mahasiswa pada periode berikutnya baik untuk untuk Program Studi Teknik Komputer maupun Manajemen
Informatika. Selanjutnya nilai prediksi tersebut akan diuji atau dihitung nilai kesalahannya dengan metode Mean Squared Error (MSE) sehingga pada akhirnya akan didapatkan nilai prediksi yang paling kecil kesalahannya. Untuk memudahkan dalam analisa dan perancangan sistem maka dapat dibuat bagan alir analisa perancangan seperti gambar dibawah ini:

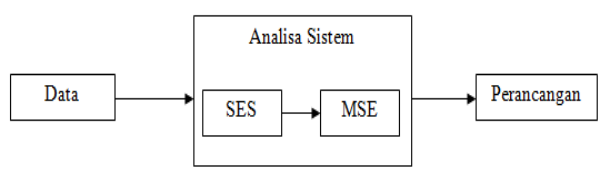

Gambar 1. Bagan Alir Analisa dan Perancangan

Data yang digunakan pada penelitian ini adalah historis data jumlah penerimaan mahasiswa baru AMIK Royal Kisaran pada 15 tahun terakhir yaitu mulai Tahun Akademik 2003/2004 sampai dengan 2017/2018 yang terdiri dari Program Studi Teknik Komputer dan Manajemen Informatika

Tabel 1. Data Penerimaan Mahasiswa Baru AMIK Royal

\begin{tabular}{cccc}
\hline \multirow{2}{*}{ NO } & TAHUN & \multicolumn{2}{c}{ PRODI } \\
\cline { 3 - 4 } & AKADEMIK & $\begin{array}{c}\text { MI } \\
\text { (Orang) }\end{array}$ & $\begin{array}{c}\text { TK } \\
\text { (Orang) }\end{array}$ \\
\hline 1 & $2003 / 2004$ & 31 & 16 \\
\hline 2 & $2004 / 2005$ & 135 & 20 \\
\hline 3 & $2005 / 2006$ & 127 & 56 \\
\hline 4 & $2006 / 2007$ & 152 & 43 \\
\hline 5 & $2007 / 2008$ & 205 & 55 \\
\hline 6 & $2008 / 2009$ & 369 & 103 \\
\hline 7 & $2009 / 2010$ & 403 & 137 \\
\hline 8 & $2010 / 2011$ & 477 & 198 \\
\hline 9 & $2011 / 2012$ & 530 & 144 \\
\hline 10 & $2012 / 2013$ & 507 & 101 \\
\hline 11 & $2013 / 2014$ & 423 & 81 \\
\hline 12 & $2014 / 2014$ & 244 & 46 \\
\hline 13 & $2015 / 2016$ & 144 & 32 \\
\hline 14 & $2016 / 2017$ & 106 & 25 \\
\hline 15 & $2017 / 2018$ & 86 & 31 \\
\hline
\end{tabular}




\section{Analisa Sistem}

Berdasarkan data historis 15 tahun terakhir, peneliti akan mencari berapa prediksi jumlah penerimaan mahasiswa baru pada Tahun Akademik 2018/2019 untuk Program Studi Teknik Komputer dan Manajemen Informatika. Nilai prediksi tersebut akan dicari menggunakan metode Single Exponential Smoothing dengan nilai alpha 0,1 sampai dengan 0,9. Kemudian karena nilai sebuah prediksi masih mengandung kesalahan. Maka akan nilai kesalahan tersebut akan dicari dengan menggunakan metode Mean Squared Error pada masing-masing nilai alphanya. Berdasarkan hasil perhitungan tersebut, hasil yang digunakan sebagai jumlah prediksi penerimaan mahasiswa baru pada Tahun Akademik 2018/2019 untuk masing-masing Program Studi adalah nilai prediksi yang memiliki nilai kesalahan yang paling kecil.

\section{Metode Single Exponential Smoothing}

Metode Single Exponential

Smoothing digunakan untuk mencari nilai prediksi. Nilai prediksi dihitung menggunakan rumus SES dengan nilai alpha 0,1 sampai dengan 0,9. Algoritma proses $S E S$ dapat dilihat dibawah ini:

1. Menyiapkan dataset

2. Melakukan perhitungan nilai prediksi dengan metode SES

3. Mendapatkan hasil nilai prediksi

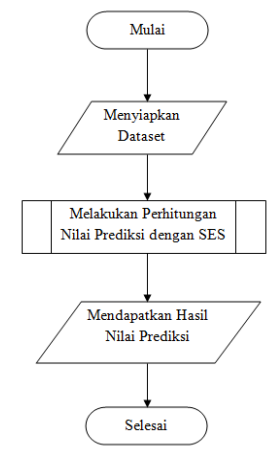

Gambar 2. Flowchart Algoritma SES
Berikut perhitungan untuk masingmasing Program Studi:

a. Perhitungan Nilai Prediksi untuk Prodi Teknik Komputer

$$
\begin{aligned}
& \text { Untuk } \boldsymbol{\alpha}=\mathbf{0 , 1} \\
& \begin{array}{rlrl}
\mathrm{F} 2 & =\alpha \mathrm{X} 1+(1-\alpha) \mathrm{F} 1 \\
& =(0,1 * 16)+(1-0,1) 16 \\
& =1,6+14,4 & \\
& =16 & \\
\mathrm{~F} 3 & =\alpha \mathrm{X} 2+(1-\alpha) \mathrm{F} 2 \\
& =(0,1 * 20)+(1-0,1) 16 \\
& =2+14,4 & \\
& =16,4 & \\
\text { F4 } & =20,36 & \mathrm{~F} 11=71,11 \\
\mathrm{~F} 5 & =22,62 & \mathrm{~F} 12=72,10 \\
\mathrm{~F} 6 & =25,86 & \mathrm{~F} 13=69,49 \\
\mathrm{~F} 7 & =33,58 & \mathrm{~F} 14=65,74 \\
\mathrm{~F} 8 & =43,92 & \mathrm{~F} 15=61,67 \\
\text { F9 } & =59,33 & \mathrm{~F} 16=\mathbf{5 8 , 6 0} \\
\text { F10 } & =67,79 &
\end{array}
\end{aligned}
$$

Perhitungan dilanjutkan hingga nilai alpha $=0,9$

b. Perhitungan Nilai Prediksi untuk Prodi Manajemen Informatika

$$
\begin{aligned}
& \text { Untuk } \boldsymbol{\alpha}=\mathbf{0 , 1} \\
& \begin{array}{rlrl}
\text { F2 } & =\alpha \mathrm{X} 1+(1-\alpha) \mathrm{F} 1 \\
& =(0,1 * 31)+(1-0,1) 31 \\
& =3,1+27,9 & \\
& =31 & \\
\text { F3 } & =\alpha \mathrm{X} 2+(1-\alpha) \mathrm{F} 2 \\
& =(0,1 * 135)+(1-0,1) 31 \\
& =13,5+27,9 & \\
& =41,4 & & \\
\text { F4 } & =49,96 & \mathrm{~F} 11=234,70 \\
\text { F5 } & =60,16 & \mathrm{~F} 12=253,53 \\
\text { F6 } & =74,65 & \mathrm{~F} 13=252,58 \\
\text { F7 } & =104,08 & \mathrm{~F} 14=241,72 \\
\text { F8 } & =133,97 & \mathrm{~F} 15=228,15 \\
\text { F9 } & =168,28 & \mathrm{~F} 16=\mathbf{2 1 3 , 9 4} \\
\text { F10 } & =204,45 &
\end{array}
\end{aligned}
$$

Perhitungan dilanjutkan hingga nilai alpha $=0,9$

Setelah dilakukan perhitungan maka akan didapatkan hasil nilai prediksi 
untuk masing-masing Program Studi pada tabel 2 dan tabel 3.

Tabel 2. Nilai Prediksi Prodi TK

\begin{tabular}{cccc}
$\boldsymbol{\alpha}$ & $\mathbf{0 , 1}$ & & \\
\hline No & $\begin{array}{c}\text { Tahun } \\
\text { Akademik }\end{array}$ & $\begin{array}{c}\text { Data } \\
\text { Aktual } \\
(\mathbf{X t})\end{array}$ & Forecast(Ft) \\
\hline 1 & $2003 / 2004$ & 16 & 16,00 \\
\hline 2 & $2004 / 2005$ & 20 & 16,00 \\
\hline 3 & $2005 / 2006$ & 56 & 16,40 \\
\hline 4 & $2006 / 2007$ & 43 & 20,36 \\
\hline 5 & $2007 / 2008$ & 55 & 22,62 \\
\hline 6 & $2008 / 2009$ & 103 & 25,86 \\
\hline 7 & $2009 / 2010$ & 137 & 33,58 \\
\hline 8 & $2010 / 2011$ & 198 & 43,92 \\
\hline 9 & $2011 / 2012$ & 144 & 59,33 \\
\hline 10 & $2012 / 2013$ & 101 & 67,79 \\
\hline 11 & $2013 / 2014$ & 81 & 71,11 \\
\hline 12 & $2014 / 2014$ & 46 & 72,10 \\
\hline 13 & $2015 / 2016$ & 32 & 69,49 \\
\hline 14 & $2016 / 2017$ & 25 & 65,74 \\
\hline 15 & $2017 / 2018$ & 31 & 61,67 \\
\hline 16 & $2018 / 2019$ & - & $\mathbf{5 8 , 6 0}$ \\
\hline & & &
\end{tabular}

Tabel 3. Nilai Prediksi Prodi MI

$\boldsymbol{\alpha}$ 0,1

\begin{tabular}{cccc}
\hline No & $\begin{array}{c}\text { Tahun } \\
\text { Akademik }\end{array}$ & $\begin{array}{c}\text { Data } \\
\text { Aktual } \\
(\mathbf{X t})\end{array}$ & Forecast(Ft) \\
\hline 1 & $2003 / 2004$ & 31 & 31,00 \\
\hline 2 & $2004 / 2005$ & 135 & 31,00 \\
\hline 3 & $2005 / 2006$ & 127 & 41,40 \\
\hline 4 & $2006 / 2007$ & 152 & 49,96 \\
\hline 5 & $2007 / 2008$ & 205 & 60,16 \\
\hline 6 & $2008 / 2009$ & 369 & 74,65 \\
\hline 7 & $2009 / 2010$ & 403 & 104,08 \\
\hline 8 & $2010 / 2011$ & 477 & 133,97 \\
\hline 9 & $2011 / 2012$ & 530 & 168,28 \\
\hline 10 & $2012 / 2013$ & 507 & 204,45 \\
\hline 11 & $2013 / 2014$ & 423 & 234,70 \\
\hline 12 & $2014 / 2014$ & 244 & 253,53 \\
\hline 13 & $2015 / 2016$ & 144 & 252,58 \\
\hline 14 & $2016 / 2017$ & 106 & 241,72 \\
\hline 15 & $2017 / 2018$ & 86 & 228,15 \\
\hline 16 & $2018 / 2019$ & - & $\mathbf{2 1 3 , 9 4}$ \\
\hline
\end{tabular}

\section{Mean Squares Error (MSE)}

Mean Squared Error digunakan untuk menghitung nilai kesalahan suatu nilai prediksi pada setiap alpha-nya sehingga nantinya akan ditemukan nilai kesalahan yang paling kecil. Algoritma proses Mean Squared Error sebagai berikut:

1. Menyiapkan dataset (Nilai Prediksi)

2. Melakukan Perhitungan nilai kesalahan dengan Metode $M S E$

3. Mendapatkan hasil nilai kesalahan

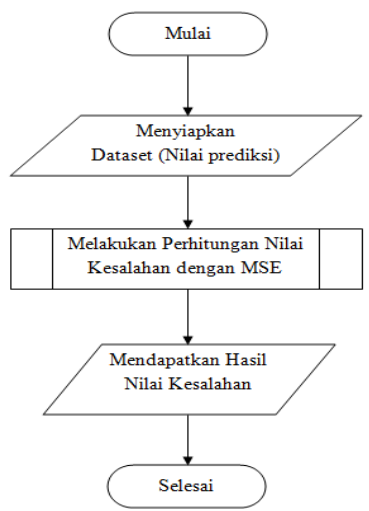

Gambar 3. Flowchart Algoritma

MSE Untuk memudahkan dalam perhitungan, maka data yang disajikan dalam bentuk tabel pada masing-masing alpha-nya (Tabel 4 dan 5). Setelah melakukan perhitungan, maka akan didapatkan nilai kesalahan sesuai dengan program studi masing-masing seperti yang tampak pada tabel berikut ini: 
JURTEKSI (Jurnal Teknologi dan Sistem Informasi)

Vol. V No. 2, Juni 2019, hlm. 125 - 132

DOI: https://doi.org/10.33330/jurteksi.v5i2.356

Available online at http://jurnal.stmikroyal.ac.id/index.php/jurteksi
ISSN 2407-1811 (Print)

ISSN 2550-0201 (Online)

Tabel 4. Tabel Perhitungan Nilai Kesalahan Prodi Teknik Komputer

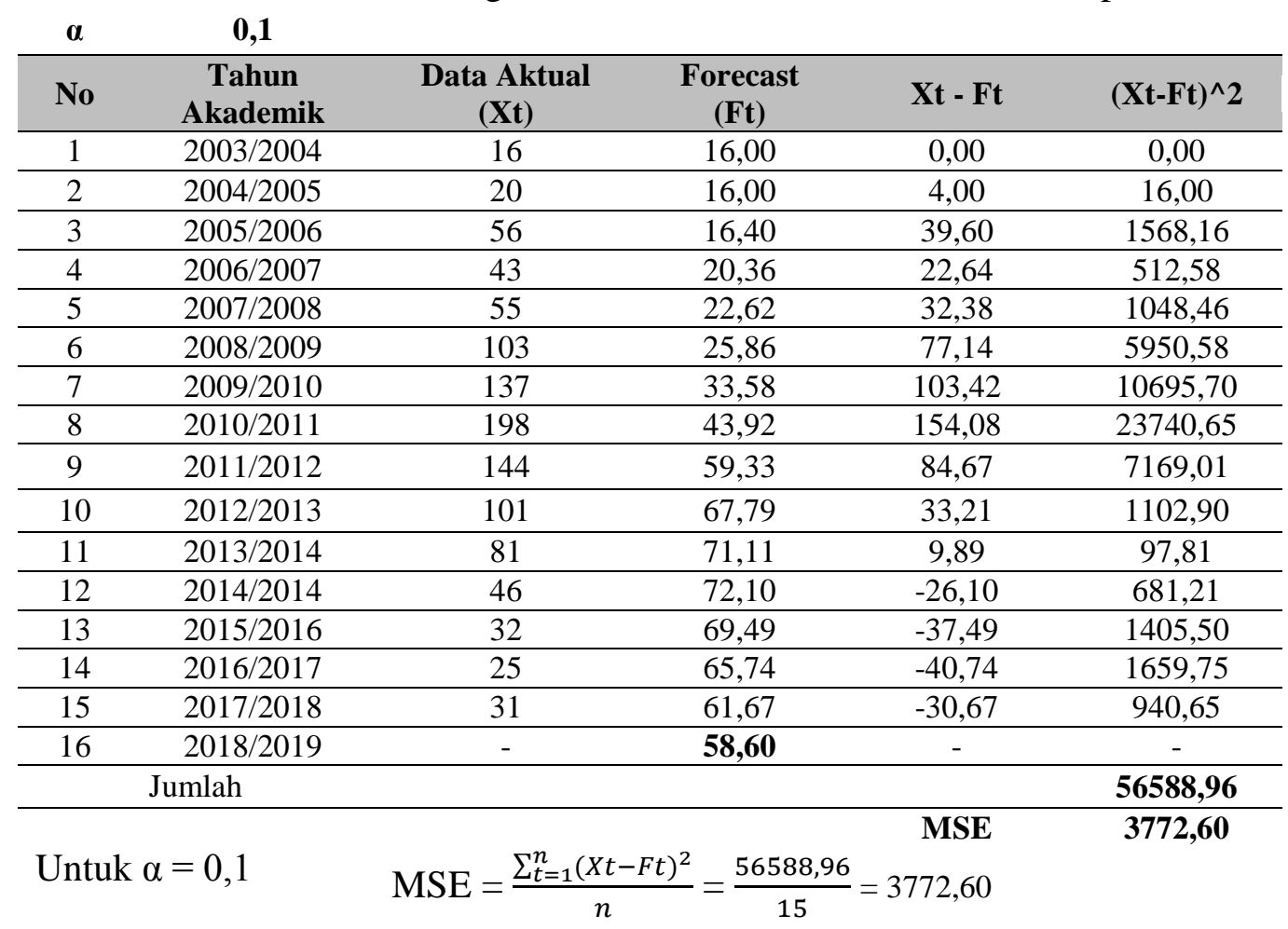

Tabel 5. Tabel Perhitungan Nilai Kesalahan Prodi Manajemen Informatika a $\mathbf{0 , 1}$

\begin{tabular}{cccccc}
\hline No & Tahun Akademik & $\begin{array}{c}\text { Data Aktual } \\
(\mathbf{X t})\end{array}$ & $\begin{array}{c}\text { Forecast } \\
(\mathbf{F t})\end{array}$ & $\mathbf{X t} \mathbf{-} \mathbf{F t}$ & $(\mathbf{X t - F t})^{\wedge} \mathbf{2}$ \\
\hline 1 & $2003 / 2004$ & 31 & 31,00 & 0,00 & 0,00 \\
\hline 2 & $2004 / 2005$ & 135 & 31,00 & 104,00 & 10816,00 \\
\hline 3 & $2005 / 2006$ & 127 & 41,40 & 85,60 & 7327,36 \\
\hline 4 & $2006 / 2007$ & 152 & 49,96 & 102,04 & 10412,16 \\
\hline 5 & $2007 / 2008$ & 205 & 60,16 & 144,84 & 20978,63 \\
\hline 6 & $2008 / 2009$ & 369 & 74,65 & 294,35 & 86641,92 \\
\hline 7 & $2009 / 2010$ & 403 & 104,08 & 298,92 & 89353,17 \\
\hline 8 & $2010 / 2011$ & 477 & 133,97 & 343,03 & 117669,58 \\
\hline 9 & $2011 / 2012$ & 530 & 168,28 & 361,72 & 130841,46 \\
\hline 10 & $2012 / 2013$ & 507 & 204,45 & 302,55 & 91536,5 \\
\hline 11 & $2013 / 2014$ & 423 & 234,70 & 188,30 & 35456,89 \\
\hline 12 & $2014 / 2014$ & 244 & 253,53 & $-9,53$ & 90,82 \\
\hline 13 & $2015 / 2016$ & 144 & 252,58 & $-108,58$ & 11789,62 \\
\hline 14 & $2016 / 2017$ & 106 & 241,72 & $-135,72$ & 18419,92 \\
\hline 15 & $2017 / 2018$ & 86 & 228,15 & $-142,15$ & 20206,62 \\
\hline 16 & $2018 / 2019$ & - & $\mathbf{2 1 3 , 9 4}$ & - & - \\
\hline & Jumlah & & & & $\mathbf{6 5 1 5 4 0 , 6 5}$ \\
\hline & & & & MSE & $\mathbf{4 3 4 3 6 , 0 4}$
\end{tabular}


DOI: https://doi.org/10.33330/jurteksi.v5i2.356

Available online at http://jurnal.stmikroyal.ac.id/index.php/jurteksi

Untuk $\alpha=0,1$

$$
\begin{aligned}
\text { MSE } & =\frac{\sum_{t=1}^{n}(X t-F t)^{2}}{n} \\
& =\frac{651540,65}{15} \\
& =43436,04
\end{aligned}
$$

Tabel 6. Tabel Nilai Kesalahan Prodi Teknik Komputer

\begin{tabular}{cc}
\hline Nilai Alpha ( $\boldsymbol{\alpha})$ & MSE \\
\hline 0,1 & 3772,6 \\
\hline 0,2 & 3053,02 \\
\hline 0,3 & 2547,21 \\
\hline 0,4 & 2133,56 \\
\hline 0,5 & 1806,99 \\
\hline 0,6 & 1555,51 \\
\hline 0,7 & 1364,13 \\
\hline 0,8 & 1219,25 \\
\hline 0,9 & 1110,77 \\
\hline
\end{tabular}

Tabel 7. Tabel Nilai Kesalahan Prodi Manajemen Informatika

\begin{tabular}{cc}
\hline Nilai Alpha $(\boldsymbol{\alpha})$ & MSE \\
\hline 0,1 & 43436,04 \\
\hline 0,2 & 31713,13 \\
\hline 0,3 & 24823,18 \\
\hline 0,4 & 19661,46 \\
\hline 0,5 & 15729,97 \\
\hline 0,6 & 12780,90 \\
\hline 0,7 & 10585,54 \\
\hline 0,8 & 8949,69 \\
\hline 0,9 & 7725,33 \\
\hline
\end{tabular}

Tabel 8. Tabel Rangkuman Nilai Prediksi dan Kesalahan Prodi TK Tahun kademik 2018/2019

\begin{tabular}{ccc}
\hline $\begin{array}{c}\text { Nilai } \\
\text { Alpha } \\
(\boldsymbol{\alpha})\end{array}$ & MSE & $\begin{array}{c}\text { Nilai Prediksi } \\
(\text { Orang) }\end{array}$ \\
\hline 0,1 & 3772,6 & $58,60=59$ \\
\hline 0,2 & 3053,02 & $59,09=59$ \\
\hline 0,3 & 2547,21 & $49,63=50$ \\
\hline 0,4 & 2133,56 & $40,83=41$ \\
\hline 0,5 & 1806,99 & $35,05=35$ \\
\hline 0,6 & 1555,51 & $31,93=32$ \\
\hline 0,7 & 1364,13 & $30,58=31$ \\
\hline 0,8 & 1219,25 & $30,26=30$ \\
\hline 0,9 & 1110,77 & $30,49=30$ \\
\hline
\end{tabular}

Tabel 9. Tabel Rangkuman Nilai Prediksi dan Kesalahan Prodi MI Tahun kademik 2018/2019

\begin{tabular}{ccc}
$\begin{array}{c}\text { Nilai } \\
\text { Alpha } \\
(\boldsymbol{\alpha})\end{array}$ & MSE & $\begin{array}{c}\text { Nilai Prediksi } \\
\text { (Orang) }\end{array}$ \\
\hline 0,1 & 43436,04 & $213,94=214$ \\
\hline 0,2 & 31713,13 & $228,29=228$ \\
\hline 0,3 & 24823,18 & $196,06=196$ \\
\hline 0,4 & 19661,46 & $159,70=160$ \\
\hline 0,5 & 15729,97 & $131,20=131$ \\
\hline 0,6 & 12780,90 & $111,85=112$ \\
\hline 0,7 & 10585,54 & $99,77=100$ \\
\hline 0,8 & 8949,69 & $92,63=93$ \\
\hline 0,9 & 7725,33 & $88,50=89$ \\
\hline
\end{tabular}

Berdasarkan tabel diatas diperoleh bahwa Pada Tahun Akademik 2018/2019 prediksi jumlah mahasiswa yang diterima untuk Program Studi Teknik Komputer sebanyak 30 Orang (Memiliki tingkat kesalahan yang terkecil $\mathrm{MSE}=1110,77$ dengan nilai alpha $=0,9$ ) dan Program Studi Manajemen Informatika sebanyak 89 Orang (Memiliki tingkat kesalahan yang terkecil $\mathrm{MSE}=7725,33$ dengan nilai alpha $=0,9$ )

\section{SIMPULAN}

Berdasarkan uraian yang telah dijelaskan, maka dapat disimpulkan beberapa hal yaitu sebagai berikut:

1. Metode Single Exponential Smoothing dapat digunakan untuk memprediksi jumlah penerimaan mahasiswa baru sehingga dapat diketahui nilai prediksi pada satu peride berikutnya.

2. Metode Mean Squared Error (MSE) dapat digunakan untuk mencari nilai kesalahan (error) pada setiap nilai 
alpha sehingga akan diperoleh nilai kesalahan yang terkecil

\section{DAFTAR PUSTAKA}

[1] Ulfa, K. N. and Syahrizal, M. (2016) 'Perancangan Aplikasi Prediksi Jumlah Siswa Baru pada Yayasan Cerdas Murni menggunakan Exponential Smoothing, Jurnal Riset Komputer (JURIKOM), 3(6), pp. 59-64.

[2] Sari, Y. and Fusfita, N. (2018) 'Peramalan Penerimaan Bea Cukai Indonesia', EKONOMIS: Jurnal of Economics and Business, 2(1), pp. 137-154.

[3] Sunarmintyastuti, L., Alfarisi, S. and Fitria Sari Hasanusi (2016) 'Peramalan Penentuan Jumlah Permintaan Konsumen berbasis Teknologi Informasi terhadap Produk Bordir pada Kota
Tasikmalaya', pp. 288-296.

[4] Kristien Margi S., S. P. W. (2015) 'Analisa dan Penerapan Metode Single Exponential Smoothing untuk Prediksi Penjualan pada Periode Tertentu (Studi Kasus : PT. Media Cemara Kreasi)', Prosiding SNATIF Ke-2, (1998), pp. 259266.

[5] Fajri, R. and Johan, T. M. (2017) 'Implementasi Peramalan Double Exponential Smoothing pada Kasus Kekerasan Anak Perempuan dan Anak di Pusat Pelayanan Terpadu pemberdayaan Perempuan dan Anak', Jurnal Ecotipe, 4(Oktober), pp. 6-13.

[6] AFRISAWATI, AFRISAWATI. "Sistem Pendukung Keputusan Penerimaan Pegawai Di Stmik Royal Metode Simple Additive Weighting." JURTEKSI 5.1 (2018):1-8. 